\title{
Learning to Lead: \\ Perceptions of Undergraduate Leadership Minor Programs
}

\author{
Tyree D. Mitchell, Ph.D. \\ Assistant Professor, School of Leadership \& Human Resource Development \\ Louisiana State University \\ Jenny Daugherty, Ph.D. \\ Leadership \& Education Consultant \\ Milwaukee, WI
}

\begin{abstract}
As leadership continues to be a targeted outcome of student learning within higher education, university faculty are left with the challenge of how to best teach and develop leadership in college students. Students are a key component of undergraduate leadership education; their motivations, learning goals, and understanding of their experiences in leadership programs. However, the research on undergraduate leadership programs from the students' perspectives is relatively scarce and limited in scope. To address this gap in the literature, we surveyed 130 current students and alumni of one leadership minor program and interviewed coordinators of seven other leadership minor programs. Our mixed methodology allowed us to capture unique insights regarding the perceived benefits and challenges of a leadership undergraduate minor.
\end{abstract}

\section{Introduction}

With the tremendous growth of leadership programs in the United States, leadership education has become a mainstay of the collegiate curriculum with several degree-granting programs from majors to minors being created and offered (Brungardt, Greenleaf, Brungardt, and Arensdorf, 2006). Haber (2012) noted that several higher education institutions have mission statements that "emphasize leadership, striving to develop students who will be leaders in various aspects of society, and a variety of leadership training, education, and development efforts are implemented on college campuses" (p. 27). As Perruci (2014) concluded with "so many different voices and programmatic inclinations, sometimes it is challenging to assess the true nature of leadership studies as an academic enterprise" (p. 43). Programs vary in their focus from understanding leadership (leadership education) to building an individual' skills (leadership training) to developing leadership abilities in all students (leadership development) (Murphy \& Johnson, 2011).

As leadership continues to be a targeted outcome of student learning within higher education, university faculty are left with the challenge of how to best teach and develop leadership in college students. Collegiate leadership programs vary greatly from where they are situated on campus (in agricultural education, engineering, business, etc.) to their mission and philosophy. Leadership is often seen as interdisciplinary or "an amalgam of the arts, humanities, and sciences" (Clegorne \& Mastrogiovanni, 2015, p. 48). Degree-granting leadership programs also vary greatly in terms of size, total number of required credit hours (for a major or minor), 
and instructional strategies. In a review of 15 leadership degree programs in 2006, Brungardt, Greenleaf, Brungardt, and Arensdorf concluded however that despite the differences in mission, the programs all emphasize the need to balance both the theory and practical applications of leadership. Leadership education involves both learning about it and developing the ability to do it. As Harvey and Jenkins (2014) argued, a common approach to teaching and learning in leadership programs is a focus on knowledge acquisition, praxis (or experiential learning), and reflection.

The similarities and differences in collegiate leadership programs reflect the faculty decisions made in designing the programs and in the development of the curriculum. The students are a key component of undergraduate leadership education; their motivations, learning goals, and experiences. However, the research on undergraduate leadership programs from the students" perspectives is relatively "sparse, and the existing studies on this topic are limited in scope" (Haber, 2012, p. 27). In order to offer better quality leadership education to college students, we need to understand students' leadership development needs and goals, as well as their understanding of leadership and experiences in leadership programs. The purpose of our study was to understand the perceived benefits and challenges/concerns of a leadership undergraduate minor from the perspective of currently enrolled students, alumni, and coordinators of leadership development minors. We surveyed 130 current students and alumni of one leadership minor program and interviewed coordinators of seven other leadership minor programs to address the following research questions:

1. What do current students, alumni, and program coordinators believe are the benefits of undergraduate leadership minor programs contributing to students' career/professional development?

2. What do current students and alumni believe are quality components of leadership minor programs?

3. What do current students, alumni, and program coordinators believe are the challenges associated with the undergraduate leadership development minor programs?

\section{Literature Review}

As discussed, the development of leadership skills is often a common core component of the leadership curriculum. However, even within this dimension to leadership education, "there are no general models for the development of leadership skills" (Lord \& Hall, 2005, p. 591) and thus a variety of approaches. Some programs have decided instead, or in conjunction with skill development, to focus on a "leadership studies" approach with goals of expanding students' knowledge of various leadership theories and research. Another focus of collegiate programs is leadership identity development, where students develop their own understanding of leadership, as well as their own sense of leadership (Komives, Owen, Longerbeam, Mainella, \& Osteen, 2005). And some programs integrate a combination of these approaches and goals. For example, Lord and Hall (2005) argued for the development of leadership skills that occurs over an extended period of time guided by students' desires to match their behaviors to theories of effective leadership and integrate their leadership skills with their identity as a leader. 
Perruci (2014) offered that a focus on leadership skills matches students' expectations in that most "students join leadership programs because they want to become a better leader, which they often define as someone who possesses strong leadership skills" (p. 44). There are a few studies that have examined students' understandings of leadership and learning outcomes. For example, Haber's (2012) mixed method study of 1,100 undergraduate students' found that they had more traditional views of leadership in that that they viewed leadership as hierarchical and leader-centric instead of collaborative. Sessa and colleagues assessed undergraduate student leaders' constructive development, leadership identity development, and understanding of leadership through interviews and surveys of 50 juniors and seniors (Sessa et al., 2016). They found that until students encounter experiences that conflict with their view of leadership, they will continue to see leadership simply as a personal characteristic and not develop a more complex understanding of leadership.

In studying the impact of leadership education on students, Rosch (2015) found few gains in the leadership capacity of 285 engineering students' after a semester-long classroom-based team experience. However, Williams, Townsend, and Linder (2005) found that students retained the same amount of knowledge comprehension of leadership for each year for three years after they took a leadership course. The students also reported using their leadership knowledge with the same regularity over the three years. In another study, Rosch and Collier (2013) examined the incoming leadership-oriented differences between 166 students enrolled in either an elective leadership studies course or an elective team-based engineering projects course to determine significant predictors of transformational leadership behavior. Students enrolled in the leadership course scored higher on measures of both transformational and transactional leadership behaviors, as well as motivation to lead.

Although these types of studies are crucial to understanding the role of leadership education in college students' understandings and development as leaders, a missing element is students' perspectives of the programs themselves. In reflecting on our own leadership development minor, we have debated the merits of a skills-based or theory-driven approach. We have discussed the challenges of delivering leadership training via online instruction and the overall learning outcomes we are targeting. In our discussions we realized the need to better understand our students' thoughts and perspectives on the program. How are they experiencing the program and what do they think are the benefits and quality aspects of the program? In these discussions, we also wanted to gain a larger perspective on the design side of leadership development programs and talk with other program coordinators about what they perceive are the benefits of their programs and what they know or think they know concerning their students' perceptions of their programs. As Rosch and Collier (2013) argued, "the more educators can understand about the types of students who elect to participate within their courses, the better they will be able to help them learn" (p. 104).

\section{Method}

Sample and Procedures. In order to answer our research questions, we used a mixed methods research design that included a short survey consisting of closed-ended and open-ended items and a semi-structured interview. We collected survey data from two different stakeholders of a leadership development minor located in the southeastern United States: current 
undergraduate students and alumni. We sent a recruitment message via email to 137 current students and 680 alumni who were awarded their degrees from 2007 to 2016. Our informed consent document stated that all responses would remain anonymous, and there would be no negative consequences associated with an individual's decision to participate (or not participate) in our research. Our informed consent document also stated that participants would be eligible to win 1 of $10 \$ 100$ cash prizes ( 5 for alumni and 5 for current undergraduate students). We sent a reminder message two weeks later to all potential participants. In terms of our response rate, we received responses from 27 students (20\% response rate) and 103 alumni (15\% response rate).

Respondents in both groups (current students and alumni) were primarily Caucasian (76\%), and female (68\%). And there was not much variation in age, with current students being in their mid-twenties $\left(M_{\text {age }}=24.52, S D_{\text {age }}=8.81\right)$ and alumni being in their late twenties $\left(M_{\text {age }}=\right.$ $27.81, S D_{\text {age }}=5.72$ ). Students represented a variety of majors (e.g., sports administration, interdisciplinary studies, english, digital advertising) and alumni represented a variety of work areas including government, sales, consulting, and education. Fifty percent of alumni indicated that they are currently in a supervisory role in which they are responsible for the work of at least one other individual.

We also conducted seven interviews of leadership development minor program coordinators at comparable university programs. The interviews provided a larger context for the understanding the student survey data and the design side of leadership education programs. Our institution had identified a list of peers for its strategic planning process, which consisted of 13 institutions that were also public universities with a land grant mission, Carnegie Research designation as Very High Research Activity, without a medical school, and located in the Midwest or South. We reviewed the websites of these peer institutions to identify comparable leadership development minors. A comparable leadership development minor program was determined to be one that is open to all students in the university and is not discipline specific (i.e., agricultural leadership or engineering leadership). We compiled a spreadsheet of all possible leadership programs and reviewed it to determine if the program met the "comparable program criteria."

Of the institutions reviewed, three appeared to not have comparable leadership development minor programs. The contact information for coordinators or key personnel for the remaining ten comparable programs was obtained. An email request was sent to these individuals requesting a brief (20-30 minute) information gathering interview to learn about the development of the leadership minor program and about the student experience. Of the ten, seven leadership minor program coordinators were interviewed using a semi-structured protocol that contained eight questions. The interviews were audio recorded and transcribed by a professional transcription service.

In order to analyze the interviews, an Excel spreadsheet was use to categorize the interview responses based on the study's research questions seeking to understand the benefits and challenges of leadership minor programs. Thus, the two primary categories were the program coordinators' responses to questions about the benefits and challenges of their leadership minor program. Another category was their responses to whether they collect student feedback on the leadership minor program, and if so, how. Direct quotes concerning the benefits 
and challenges were entered into each cell of the spreadsheet for each program. The program coordinators' responses to how they collect student feedback was summarized on the spreadsheet. We then reviewed the direct quotes and summaries captured on the spreadsheet and identified consistent responses or themes.

Another category on the spreadsheet was the "story of the leadership minor program," which included the program coordinators' explanation of why the program was developed, when it was developed, where it was housed in the university, and how it was currently being managed. A summary of the story was developed by one of the researchers after reading each response several times and entered into the spreadsheet, along with pithy or interesting direct quotes. The "approach to leadership education" was an additional category that was used to capture how the program was teaching leadership whether from a defined model or another approach. Again, a summary of each program's approach was developed by the researcher based on the program coordinator's response and entered into the spreadsheet.

\section{Results}

Program Descriptions. Our leadership development minor program first started offering courses in 2006 and it currently consists of 12 hours of core leadership courses and 6 hours of electives from an approved list. The leadership development minor is open to any undergraduate student at the university. The core leadership courses are primarily web-based and focus on core concepts and principles of leadership. The core courses also require students to complete a variety of assessments that help them better understand their personal values and characteristics as it relates to leadership development. Students are also required to complete an internship that allows them to integrate their coursework with practical leadership experience. The electives allow undergraduate students the opportunity to enroll in various courses across the university to supplement their core leadership coursework.

Of the seven programs we interviewed the program coordinators, the oldest was estimated to have started "20-25 years ago" and the most recent was launched last year. Almost all of the program coordinators pointed to the impetus for the creation of the leadership minor program being a core value of the institution often identified in the university's strategic plan or as one coordinator stated, leadership "kind of became the buzz word." Another coordinator stated, "so there's a been a big push for we have a transformative very accessible philosophy of leadership education, and we realize the value added of leadership courses and realize that not every student can declare a leadership major." Another impetus identified by two of the programs were faculty interest and expertise in leadership development. As one program coordinator stated, our vision was to create "an experiential learning academic experience that focused on college student leadership and transition that to their post college experience."

The approach to leadership development taken by the minor programs varied somewhat. Although our program does not adhere to a specific leadership model, it does integrate a focus on assessment where students identify their strengths and weaknesses in an assessment center. Students then learn leadership concepts and principles and are provided an opportunity to apply these skills in a service learning course, as well as during an internship. A few of the program coordinators we interviewed identified specific models or theories. Three of the coordinators 
pointed to the social change model as at least one element of their approach to leadership. One coordinator stated that the social change model guides the "learning outcomes we wish our students to experience." One of the programs is in the middle of an assessment to examine whether this is still the appropriate underpinning of the program. They currently approach leadership development as mindsets; "some of the mindsets that we've identified is learning mindset, community mindset, a justice mindset, and an action mindset." Another coordinator pointed to the leadership theories identified in Northouse (2018), as well as a set of competencies they identified as their foundation.

Three of the program coordinators said they did not use a specific model. One of the programs takes a "holistic approach" in that they use "a little bit of skills, context, behaviors, theories, current issues and then practical application." Another program coordinator indicated that "we do have more of a kind of community and community theory base, so interactional theory and that sort of stuff, where it's really about the process of community and capacity building." The other program coordinator said they did not use a specific leadership framework but identified the interdisciplinary nature of the program as foundational. The coordinator stated that we are "trying to meet the needs of employers as well as trying to get the students to bridge that gap of what employers are seeing as lacking in their skills and knowledge and understanding and trying to help them make those connections."

RQ 1. Perceived Benefits of Leadership Minors. We asked the coordinators of the leadership minor programs what they thought their students believed were the benefits of the minor. Five of the program coordinators discussed gauging students' perceptions via surveys; three of which specified they conducted exit or senior surveys. Two program coordinators stated that in addition to surveys they have conducted focus groups of graduating students and one of these coordinators mentioned doing an alumni survey as well. This program coordinator explained they had recently conducted a formal program evaluation of the leadership minor. Two of the seven program coordinators cited anecdotal evidence when answering this question, as they did not conduct any formal feedback methods.

All of the program coordinators referenced students' career/professional development as a benefit of the program. Three of the program leaders specifically identified the students' acquiring "a leadership language" to use in their careers. As one program coordinator stated, the program alumni they interviewed said they valued "their ability to name phenomena that is happening, and then identify the tools needed to navigate that space." Two other program coordinators responded that this language was beneficial to alumni of their programs as they participated in interviews; "they felt light years better prepared than their peers." Related to this notion of a leadership language, is the benefit of listing a leadership minor on a students' resume which was identified by five of the coordinators.

Given the coordinators' focus on leadership programs benefiting students' career/professional development, we asked alumni and currently enrolled students specifically how the leadership development minor contributed to their career/professional development. An overwhelming majority of the open-ended comments from both alumni and current students were related to how the minor enhanced their knowledge and skills necessary for effective leadership. For example, one alumni stated, that "I find that I'm very aware of how I manage my employees 
because of this minor." Another credited the minor with giving "me leadership techniques I implement every day at my current job." Pointing to the idea of a "leadership language," another alumni noted the impact of the minor in "being able to effectively communicate and negotiate with clients, coworkers, superiors, etc." A current student commented that the minor is helping her or him "to be able to take responsibility and lead others with confidence."

In addition to developing their leadership knowledge and skills, 14 of the alumni mentioned how the leadership development minor enhanced their marketability to employers and helped with career advancement. One alumni stated that "a past employer admitted that the leadership development minor and the skills I obtained from the courses are what landed me the job." Another alumni pointed to the minor as contributing to "getting a promotion 11 months into my career." From landing a job to promotions, several alumni credited being able to list the leadership minor on their resumes as contributing to their career advancement opportunities. One alumni even stated that the leadership minor "was one of the best educational decisions I made." Current students echoed these alumni comments, in the hope that the leadership minor will set them apart. One student believed that "it will contribute to my ability to be competitive in interviews and the job market." Another student is "hoping that it may put me in a position to be promoted quickly once in the workforce."

RQ 2. Quality Components of Leadership Minors. The identification of benefits to students' career/professional development begs the question of what components of the leadership minor students and alumni perceive as important for a quality program. We posed this question directly to current students and alumni. Using a Likert-type scale anchored at 1 ("unimportant") and 5 ("very important"), we asked current students and alumni to rate components of the leadership development minor program (see Figure 1 below). Current students and alumni identified the availability of internships $(M=4.45, S D=.73, N=126)$ and faculty teaching effectiveness $(M=4.68, S D=.65, N=126)$ as the two most important components of the leadership minor. Current students and alumni reported rather neutral or indifferent feelings about the importance of facilities $(M=3.68, S D=.95, N=126)$, low studentto-faculty ratio $(M=3.62, S D=1.01, N=125)$, the research productivity of faculty $(M=3.66, S D$ $=.84, N=126)$, and having prestigious faculty affiliated with the minor $(M=3.50, S D=.91, N=$ 126). In testing for significant differences between alumni and current students regarding perceptions of quality components of leadership minors, we observed that alumni rated the availability of internships as higher in importance than current students. There were no other significant differences between alumni and current students regarding perceptions of quality components of a leadership minor. 


\section{Students' Perceptions of Quality Components of Leadership Minors}

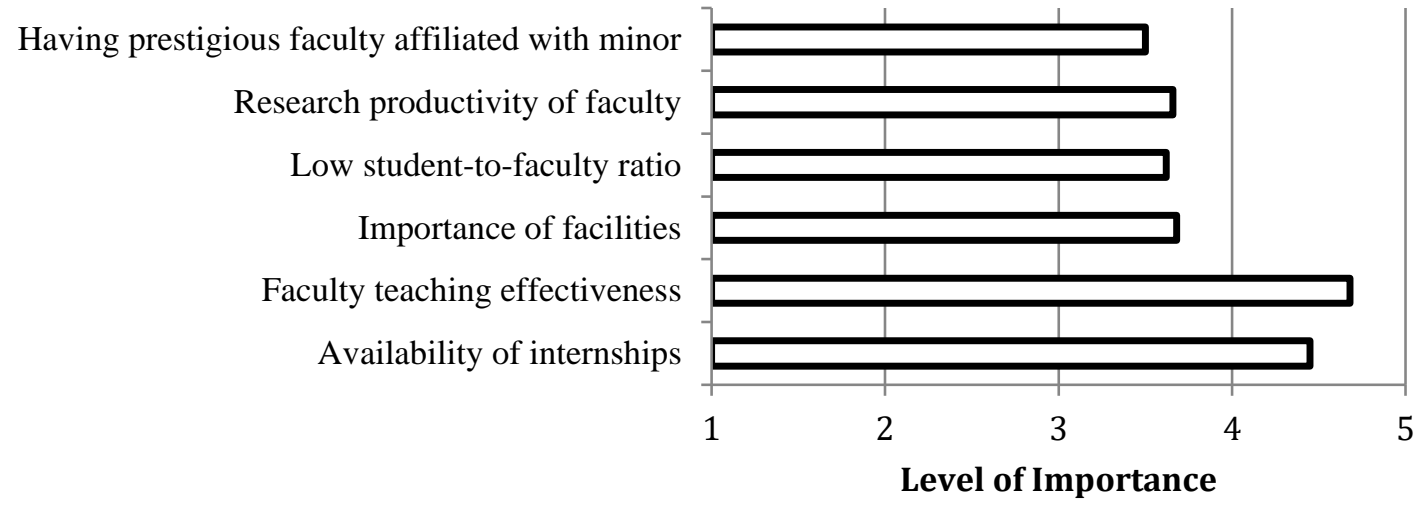

Figure 1. Students' Perceptions of Quality Components of Leadership Minors

We also asked current students and alumni to indicate how valuable, rigorous, and prestigious the leadership development minor is in comparison to other types of minors (see Figure 2 below). All items used a Likert-type scale anchored at 1 ("strongly disagree") and 5 ("strongly agree"). Current students and alumni agreed that in comparison to other types of minors, the leadership development minor is valuable $(M=4.01, S D=.91, N=124)$. However, current students and alumni did not agree that the leadership development minor is rigorous in comparison to other types of minors $(M=2.70, S D=1.04, N=124)$. Current students and alumni were rather indifferent regarding the statement that the leadership development minor is prestigious in comparison to other types of minors $(M=3.14, S D=.86, N=124)$. In testing for significant differences between alumni and current students regarding perceptions of the leadership minor in comparison to other types of minors, we observed that alumni (in comparison to current students) rated that the leadership minor as less rigorous. There were no other significant differences between alumni and current students regarding perceptions of the leadership minor in comparison to other types of minors. 


\section{Students' Perceptions of the Leadership Minor in Comparison to Other Types of Minors}

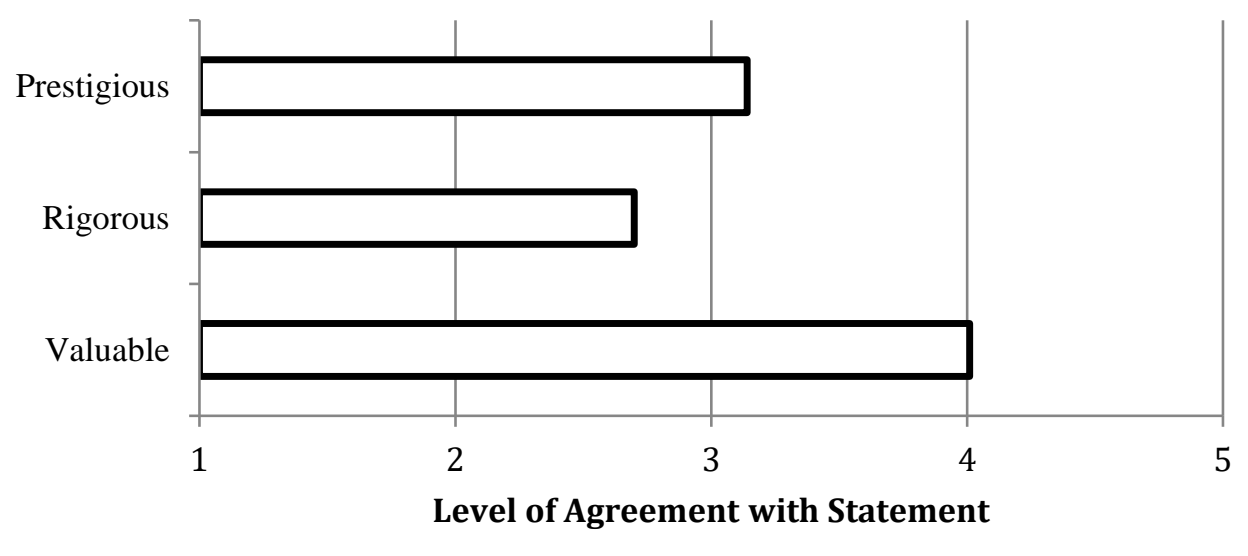

Figure 2. Students' Perceptions of the Leadership Minor in Comparison to Other Types of Minors

RQ 3. Challenges of Leadership Minors. In thinking about improving the quality and further benefiting students, we wanted to identify particular challenges encountered in delivering and experiencing the leadership minor. Although we did not specifically ask about challenges, we did ask current students and alumni to offer suggestions for improving of the minor. The majority of students and alumni (11) focused on the web-based nature of the minor. Many pointed to the lack of in person interaction in courses. As one student commented, "I think it would've been a lot better if it wasn't online and we had more face-to-face interactions with other classmates." Although students identified this as a challenge, many also noted the benefits of having the courses online. As one student stated, "I understand the convenience of the minor being offered online, and it fit into my schedule as a student very well. I do think that...seeing and learning in-person could be really helpful."

The other suggested area of improvement identified by nine of the students and alumni was the internship capstone course. Current students and alumni felt that there should be more guidance through the internship process and more realistic requirements for the internship. An alumni offered that "I think the internships could be taken more seriously, but students need more guidance on how to find the right fit." A current student commented that they thought "the requirements for the type of internship is unrealistic." Similarly another student pointed to several factors that make the 144-hour requirement for the internship challenging, "I work a job, am enrolled full time in school, and am heavily involved in a campus organization."

We asked coordinators what they believed are the challenges associated with the undergraduate leadership development minor programs. All but one of the program coordinators pointed to issues of managing and delivering the programs. An often-identified issue pertained to the lack of resources to support the programs and manage growth. Three of the program 
coordinators spoke specifically to the need for instructors to teach and transition courses to an online format. One coordinator spoke of this need stating that, all of the instructors are limitedterm lecturers. Four of the coordinators discussed the pressure of offering more online course options in the minor program. One of the coordinators highlighted the need to "really making sure that the quality of education they're getting online is matching that to what they would get if they were a major student taking the courses face-to-face."

Another area that three of the program coordinators identified as problematic was related to the curriculum of the programs. Two coordinators spoke to the need to continually update and maintain a consistent curriculum, as well as attend to "the national conversation around leadership education" - which is focused more on equity inclusion, power/privilege, a critical lens." In terms of the curriculum, another coordinator mentioned the interdisciplinary nature of the program leading to challenges in "working across colleges" and the fact that "some of the classes aren't always in our control, and some not following a standard curriculum."

Another challenge two of the program coordinators described was in recruiting and advising students. One coordinator commented that due to other leadership minor programs emerging on campus, "students confuse them if not differentiated well." Two program coordinators spoke to challenges working with advisors to understand and communicate the program requirements to students. One coordinator stated that "a lot of times we don't get the support from the advisors in the other colleges even though we try." Another commented that "one of the biggest challenges is that students can join this program whenever and they wait until the last semester and there are just not enough seats in classes they need." Another coordinator summed this challenge up by stating, "so for us that means we constantly have to make sure that we are recruiting and the advisors are helping us get students into the program and we're successfully graduating our students."

\section{Discussion}

Although the sample size from our survey and interviews was relatively small, we believe we were able to capture unique insights that further our understanding about the impact of leadership development minors from various stakeholders' perspectives. It is worth noting that we contacted alumni who received their degrees as early as 2007 capturing to some degree the long-term impact of the leadership development minor on their careers. From the alumni, current students, and program coordinators, we identified perceived benefits, quality components, and challenges of a leadership minor. We hope this adds to the discussion around collegiate leadership education as we pursue effective leadership education "to prepare people to deal with the diverse reality present in a pluralistic world" (Watt, 2003, p. 14).

The benefits of leadership minors as identified by the program coordinators focused primarily on contributing to students' career/professional development, even though the programs varied in terms of approach. This perceived benefit is reflected in Stephens and Beatty's (2015) belief that leadership education has "the potential to dramatically shape students' trajectory in college and beyond" (p. 119). Alumni participating in this study reported actual benefits to their career trajectories, identifying jobs secured and promotions obtained as evidence. However, more research is needed to determine how, and in what ways, leadership 
education is impacting students' leadership skills and abilities in their careers. Beyond obtaining the job or promotion, how does the program enable students to lead effectively? Another key question, posed by Grimes (2015), is "While students may adopt the necessary skills to function well in their particular leadership roles, are they experiencing the depth of thinking that we as leadership educators hope for?" (p. 39). Although we did have participation from alumni who had graduated a decade before, future research is needed to understand the long-term effects of leadership programs on individuals' thinking, as well as their career and leadership development.

This type of research would also inform and refine the curriculum and instruction of leadership programs. In our study, current students and alumni shared similar perspectives about the curricular components of the leadership development minor. Faculty teaching effectiveness and availability of internships were considered to be the most important benchmarks of a quality leadership development minor. Perhaps the most interesting finding was that while students and alumni appreciate the web-based nature of the minor in terms of ease and availability, they desired more in-person interaction with other students and the instructors. This finding is particularly interesting in light of the recent trends in higher education with institutions offering more web-based courses and programs. Several of the program coordinators pointed to this tension the students identified commenting on a "push" to integrate more online courses but struggling with how to teach leadership effectively in an online environment. Research is needed to explore how students learn leadership in web-based environments and the potential trade-offs of offering web-based leadership programs.

Our findings support Perucci's (2014) beliefs that the majority of students join leadership programs to become better leaders and provided their perspectives on the programs' benefits. We hope the study's findings can encourage researchers to further investigate the benefits and impact of leadership programs in higher education. Similarly, we hope that program coordinators and researchers report information about their programs, including the program design, curriculum and instruction, and approaches to leadership. As Haber (2012) argued, as "colleges and universities continue to strive to develop students who are leaders and capable of leading and affecting change, it is important that institutional leaders clarify what values around leadership they seek to develop in their students" (Haber, 2012, p. 46). 


\section{References}

Brungardt, C., Greenleaf, J., Brungardt, C., \& Arensdorf, J. (2006). Majoring in leadership: A review of undergraduate leadership degree programs. Journal of Leadership Education, 5, 4-25. DOI: $10.12806 / \mathrm{v} 5 / \mathrm{i} 1 / \mathrm{rf1}$

Clegorne, N. A. \& Mastrogiovanni, J. M. M. (2015). Designing alternatives: Design thinking as a mediating learning strategy to bridge science and the humanities for leadership learning, Journal of Leadership Education, 14, 46-54.

Grimes, M.W. (2015). How does learning in leadership work? A conceptual change perspective. Journal of Leadership Education, 14, 26-45.

Haber, P. (2012). Perceptions of leadership: An examination of college students' understanding of the concept of leadership. Journal of Leadership Education, 11, 26-51. DOI: $10.12806 / \mathrm{v} 11 / \mathrm{i} 2 / \mathrm{rf} 2$

Harvey, M., \& Jenkins, D. M. (2014). Knowledge, praxis, and reflection: The three critical elements of effective leadership studies programs. Journal of Leadership Studies, 7, 7685. doi: $10.1002 / \mathrm{jls} .21314$

Komives, S. R., Owen, J. E., Longerbeam, S. D., Mainella, F. C., \& Osteen, L. (2005). Developing a leadership identity: A grounded theory. Journal of College Student Development, 46, 593-611.

Lord, R. G., \& Hall, R. J. (2005). Identity, deep structure and the development of leadership. The Leadership Quarterly, 16, 591-615.

Murphy, S. E., \& Johnson, S. K. (2011). The benefits of a long-lens approach to leader development: Understanding the seeds of leadership. The Leadership Quarterly, 22, 459470 .

Northouse, P. G. (2018). Leadership: Theory and Practice, $8^{\text {th }}$ Edition. Los Angeles, CA: Sage.

Perruci, G. (2014). Leadership education across the disciplines: The social science perspective. Journal of Leadership Studies, 7, 43-47.

Rosch, D. (2015). Effects of classroom-based team experiences on undergraduate student leadership development: When practice does not make perfect. Journal of Leadership Education, 14, 104-118.

Sessa, V. I., Ploskonka, J., Alvarez, E. L., Dourdis, S., Dixon, C., \& Bragger, J. D. (2016). The relationship between student leaders' constructive development, their leadership identity, and their understanding of leadership. Journal of Leadership Education, 15, 15-30. 
Stephens, C. M., \& Beatty, C. C. (2015). Leading and thriving: How leadership education can improve first-year student success. Journal of Leadership Education, 14, 119-131.

Watt, W. M. (2003). Effective leadership education: Developing a core curriculum for leadership studies. Journal of Leadership Education, 2, 13-26.

\section{Author Biographies}

Dr. Tyree Mitchell is an Assistant Professor in the School of Leadership \& Human Resource Development at Louisiana State University. He holds a Ph.D. in Industrial/Organizational Psychology from DePaul University. His research in the area of leadership primarily focuses on understanding the antecedents of leadership emergence in selfmanaging teams. tyreemitchell@1su.edu.

Dr. Jenny Daugherty is a leadership and education consultant and program evaluator for various projects. She is focused on developing solutions and improving practices that build learning capacity and leadership capability in individuals and organizations. Her experience over the last several years in academia as a professor, researcher, and director have equipped her with strategic planning, collaboration, and project management skills. jennydaugherty@gmail.com. 